\title{
Prevalence of congenital hydrocephalus in the Hashemite kingdom of Jordan: A hospital-based study
}

\author{
Hana Dawood Ali Alebous ${ }^{1 *}$, Abeer Ahmad Hasan ${ }^{2}$ \\ ${ }^{1}$ Department of Biology, University of Jordan, Amman, Jordan; ${ }^{*}$ Corresponding Author: Ayham_suhail@yahoo.com \\ ${ }^{2}$ Department of Pediatrics, Al Bashir Hospital, Amman, Jordan
}

Received 23 August 2012; revised 24 August 2012; accepted 10 September 2012

\begin{abstract}
Background: Congenital hydrocephalus, an important cause of neurologic morbidity and mortality in children, is a medical condition characterized by an abnormal accumulation of cerebrospinal fluid in the brain. It can be caused by abnormal brain development, obstruction of the cerebral aqueduct flow, Chiari malformations, and Dandy-Walker malformation. The prevalence of congenital hydrocephalus is 2.2 to 18 per 10,000 live births. Objectives: To determine the prevalence of congenital hydrocephalus among livebirths in the Hashemite Kingdom of Jordan (HKJ). Methods: Clinical data were collected from medical records of all livebirths with congenital hydrocephalus born at Al Bashir Hospital, Amman/The Hashemite Kingdom of Jordan in 2004-2005 and 2008-2011. Descriptive analysis was carried out using the Statistical Package for the Social Science (SPSS 20). Results: The prevalence of hydrocephalus was $0.092 \%$ with a relative predominance among males. Conclusion: The study concluded that the prevalence of congenital hydrocephalus is comparable to that of developed countries. The efforts made by the Ministry of Health seem to have paid off. More research on stillbirths is recommended.
\end{abstract}

Keywords: Congenital Hydrocephalus; Prevalence; Hashemite Kingdom of Jordan

\section{INTRODUCTION}

To date, this study is, to the best of the researchers' knowledge, the first to report on the prevalence of congenital hydrocephalus diagnoses in the Hashemite Kingdom of Jordan (HKJ). Its findings can raise physiccians' awareness of the status of congenital hydrocepha- lus prevalence as a requirement for further possible interventions.

The study addressed congenital hydrocephalus prevalence among all infants born at $\mathrm{Al}$ Bashir Hospital after obtaining the hospital's approval for the conduct of the study. This hospital, located in the capital city Amman, is the largest Ministry of Health facility with more than 1000 beds. Al Bashir is a referral hospital for patients with Ministry of health government insurance countrywide [1]. The study covered a 6-year period. Although the HKJ is a small developing country in the Middle East with a rapidly growing population of 5.7 million, it enjoys a good system of health care; no less than $80 \%$ of the population can reach a facility in 30 minutes or fewer [2]. This study, to date, is the first to provide researchers with best information concerning the prevalence of congenital hydrocephalus in the HKJ.

Hydrocephalus can arise from various conditions such as congenital malformations of the central nervous system (CNS) and also may be acquired after perinatal events such as tumours, cerebral bleeding, and CNS infections $[3,4]$.

Congenital hydrocephalus is a medical condition characterized by an abnormal accumulation of cerebrospinal fluid in the brain [5]. Abnormal brain development, obstruction of the cerebral aqueduct flow, Chiari malformations, and Dandy-Walker malformation can lead to congenital hydrocephalus $[3,6]$.

Congenital hydrocephalus is an important cause of neurologic morbidity and mortality in children; however, the widespread use of surgical shunt therapy reduced mortality [7]. Although the prevalence of congenital hydrocephalus is usually reported as 1 per 1000 , a thorough review of the extant literature suggests that it ranges between 2.2 [3] to18 per 10,000 [11].

Congenital hydrocephalus is usually detected early in gestation during routine prenatal examinations using ultrasound scans; however, in some cases the hydroce- 
phalus is only visible later in gestation [3]. It seems undeniably true that Jordanian citizens are likely to avoid any termination of pregnancy due to not only cultural understanding and social beliefs but also on legal grounds [8]. Thus, it is a tough decision for parents to make i.e., whether to continue or terminate the pregnancy especially when the diagnosis is made later in gestation.

\section{PATIENTS AND METHODS}

The study aimed to be a retrospective review of the congenital hydrocephalus case notes in the HKJ over an 8-year period (2004-2011). Due to a construction process the target hospital underwent, it was inconvenient to obtain data about the years of 2006 and 2007. Thus, the study covered six years (2004-2005 and 2008-2011). Data were collected from Al Bashir Hospital, a major public referral hospital in the capital city, Amman.

The data for this study were based on the hospital labor records that routinely include birth date and weight (gram), sex, mode of delivery, gestation age, Apgar score, and diagnosis. Although congenital hydrocephalus may be acquired after perinatal events, all cases included in this study were of newborns diagnosed with congenital hydrocephalus using ultrasound investigations during 18 - 20 weeks of gestation and confirmed after birth.

Prevalence of congenital hydrocephalus was calculated as the percentage of cases diagnosed with congenital hydrocephalus to the total number of live births each year. After the number of cases diagnosed with congenital hydrocephalus was identified, the percentages of male and female cases and difference in infected female/male ratio were calculated per year. Data were fed into Statistical Package for the Social Science (SPSS 20) software and analyzed using descriptive analysis.

\section{RESULTS}

The cases of this study comprised a total of 88,815 live births. Both birth date and sex were collected for each case. Among this total, infants identified as born with congenital hydrocephalus were 82 (33 females, 49 males). Prevalence and sex ratio were compared by congenital hydrocephalus.

The data collected about the prevalence of congenital hydrocephalus over the six years in Table 1 indicated that among the total of 88,815 live births, 82 cases were diagnosed with congenital hydrocephalus during birth hospitalization, providing a prevalence of $0.092 \%$. The ratio of diagnosed cases ranged between $0.068 \%$ (during 2010) and $0.139 \%$ (during 2004).

The results related to the prevalence of congenital hydrocephalus according to gender presented in Table 2 indicated a general tendency toward a higher prevalence rate among males; this was true in four of the six years.
Table 1. Number and prevalence of congenital hydrocephalus and the year of occurrence.

\begin{tabular}{cccc}
\hline Year & $\begin{array}{c}\text { Total number of } \\
\mathrm{CH}^{\mathrm{a}}\end{array}$ & $\begin{array}{c}\text { Total No. of } \\
\text { live births }\end{array}$ & $\begin{array}{c}\text { Prevalence of } \\
\mathrm{CH}^{\mathrm{a}}\end{array}$ \\
\hline 2004 & 18 & 12960 & $0.139 \%$ \\
2005 & 10 & 13191 & $0.076 \%$ \\
2008 & 18 & 17522 & $0.103 \%$ \\
2009 & 17 & 18763 & $0.091 \%$ \\
2010 & 9 & 13088 & $0.068 \%$ \\
2011 & 10 & 13291 & $0.075 \%$ \\
Total & 82 & 88815 & $0.092 \%$ \\
\hline
\end{tabular}

${ }^{\mathrm{a}}$ Congenital Hydrocephalus.

Table 2. Sex ratio in the prevalence of congenital hydrocephalus.

\begin{tabular}{cccc}
\hline Year & $\begin{array}{c}\text { No. and percentage } \\
\text { of females with } \\
\mathrm{CH}^{\mathrm{a}}\end{array}$ & $\begin{array}{c}\text { No. and } \\
\text { percentage of } \\
\text { males with } \\
\mathrm{CH}^{\mathrm{a}}\end{array}$ & $\begin{array}{c}\text { Difference in } \\
\text { infected } \\
\text { female/male } \\
\text { ratio }\end{array}$ \\
\hline 2004 & $7(38.9 \%)$ & $11(61.1 \%)$ & $22.2 \%$ \\
2005 & $5(50.0 \%)$ & $5(50.0 \%)$ & $0 \%$ \\
2008 & $7(38.9 \%)$ & $11(61.1 \%)$ & $22.2 \%$ \\
2009 & $5(29.4 \%)$ & $12(70.6 \%)$ & $41.2 \%$ \\
2010 & $5(55.6 \%)$ & $4(44.4 \%)$ & $-11.2 \%$ \\
2011 & $4(40.0 \%)$ & $6(60.0 \%)$ & $20 \%$ \\
Total & $33(40.2 \%)$ & $49(59.8 \%)$ & $19.8 \%$ \\
\hline
\end{tabular}

${ }^{\mathrm{a} C}$ Congenital Hydrocephalus.

In the other two years, there was no difference in one (2005) and a difference in favor of females (2010). The maximum difference was in 2009, with a ratio difference of $41.2 \%$.

\section{DISCUSSION}

By analyzing the data, we found a prevalence of congenital hydrocephalus at $0.092 \%$ during $2004-2005$ and 2008-2011. Due to the absence of previous research findings at a local level, there is no local reference to compare with. However, a comparison between our finding and previous research findings indicates that ours falls within the range of previously reported prevalence rates in developed countries, which ranges between 2.2 and 18 per 10,000 live births [3,9-14].

Our results suggest that there is a general tendency toward decline in the prevalence of congenital hydrocephalus during the period of time this study covered. This general decline in diagnoses of congenital hydro- 
cephalus during more recent years in the HKJ can possibly be attributed to the increasing awareness among Jordanian families and medical service providers manifest in the establishment of new centers for family medicine providing maternal services. Clearly, Jordanian families can benefit from health care services delivered by a large body of medical systems that include the Ministry of Health system, the private sector, the military health system, and nongovernmental organizations [2]. Another possible factor behind this decline is the introduction of folic acid enrichment of food [7] that started in the HKJ in 2002 [8].

Our study findings also suggest a relative higher prevalence among males. This finding goes in line with the findings of other researchers $[7,15]$. It is reported that male births had an overall malformation prevalence of 28.6\% higher than females' [15]. Many scholars suggest several possible considerations [15]. The first is the possible interference of hormonal and physiologic sex differences subsequent to gonadal differentiation. Another possible justification may lie in that X-and Y-linked genes may play a role in shaping the normal development of structures besides sex-related structural development. There is also a possible interference from the fact that male embryos grow faster than female embryos. One more possibility relates to the variable concentrations of parent sex hormones near the time of conception.

It should be noted that this was limited to livebirths at only one major referral hospital. In addition, since cases of fetal death at the beginning of gestation were discarded without being studied, it is probable that the real prevalence of congenital hydrocephalus was underestimated. Unfortunately, there is no account of how often abortions are performed among mothers of hydrocephalic fetuses. The incidence rate of such cases is believed to vary between 0.2 and 1 per 1000 live births [16]. Thus, the researchers recommend further research addressing the prevalence of congenital hydrocephalus among livebirths and stillbirths at a wider scope of health facilities.

\section{ACKNOWLEDGEMENTS}

The authors would like to thank the administration and staff at $\mathrm{Al}$ Bashir Hospital for their support and assistance.

\section{REFERENCES}

[1] El-Salem, K. et al. (2006) Multiple sclerosis in Jordan: A clinical and epidemiological study. Journal of Neurology, 253, 1210-1216. doi:10.1007/s00415-006-0203-2

[2] Al-Qutob, R. and Nasir, L. (2008) Provider perceptions of reproductive health service quality in Jordanian public community health centers. Health Care for Women Inter- national, 29, 539-550. doi:10.1080/07399330801949657

[3] Garne, E. et al. (2010) Congenital hydrocephalus-prevalence, prenatal diagnosis and outcome of pregnancy in four European regions. European Journal of Paediatric Neurology, 14, 150-155. doi:10.1016/j.ejpn.2009.03.005

[4] Schrander-Stumpel, C. and Fryns, J.P. (1998) Congenital hydrocephalus: Nosology and guidelines for clinical approach and genetic counseling. European Journal of Pediatrics, 157, 355-362. doi:10.1007/s004310050830

[5] Sadler, T.W. (2010) Langman's medical embryology. 11th Edition, Lippincott Williams \& Wilkins, Baltimore.

[6] Sun, G., Xu, Z.M., Liang, J.F., Li, L. and Tang, D.X. (2011) Twelve-year prevalence of common neonatal congenital malformations in Zhejiang Province, China. World journal of pediatrics, 7, 331-336. doi:10.1007/s12519-011-0328-y

[7] Jeng, S., Gupta, N., Wrensch, M., Zhao, S. and Wu, Y.W. (2011) Prevalence of congenital hydrocephalus in California, 1991-2000. Pediatric Neurology, 45, 67-71. doi:10.1016/j.pediatrneurol.2011.03.009

[8] Amarin, Z. and Obeidat, A. (2010) Effect of folic acid fortification on the incidence of neural tube defects. Paediatric and Perinatal Epidemiology, 24, 349-351. doi:10.1111/j.1365-3016.2010.01123.x

[9] Miller, J.M. and McAllister II, J.P. (2007) Reduction of astrogliosis and microgliosis by cerebrospinal fluid shunting in experimental hydrocephalus. Cerebrospinal Fluid Research, 4, 5. doi:10.1186/1743-8454-4-5

[10] Clewell, W.H. (1988) Congenital hydrocephalus: Treatment in utero. Fetaltherapy, 3, 89-97.

[11] Kohn, D.F., Chinookoswong, N. and Chou, S.M. (1981) A new model of congenital hydrocephalus in the rat. Acta Neuropathologica, 54, 211-218. doi:10.1007/BF00687744

[12] Christensen, J.H., Hansen, L.K. and Garne, E. (2003) Congenital hydrocephalus-prevalence and prognosis. Mortality and morbidity in a population-based study. Ugeskrift for laeger, 165, 466-469.

[13] Dietrich, P., Shanmugasundaram, R., Shuyu, E. and Dragatsis, I. (2009) Congenital hydrocephalus associated with abnormal subcommissural organ in mice lacking huntingtin in Wnt1 cell lineages. Human molecular genetics, 18, 142-150. doi:10.1093/hmg/ddn324

[14] Stoll, C., Alembik, Y., Dott, B. and Roth, M. (1992) An epidemiologic study of environmental and genetic factors in congenital hydrocephalus. European journal of epidemiology, 8, 797-803. doi:10.1007/BF00145322

[15] Shaw, G.M., Carmichael, S.L., Kaidarova, Z. and Harris, J.A. (2003) Differential risks to males and females for congenital malformations among 2.5 million California births, 1989-1997. Birth Defects Research. Part A, Clinical and Molecular Teratology, 67, 953-958. doi:10.1002/bdra.10129

[16] Cavalheiro, S. et al. (2011) Fetal hydrocephalus. official Journal of the International Society for Pediatric Neurosugery, 27, 1575-1583. 